\title{
Acute pulmonary vein isolation lesions consist of interstitial oedema and tissue necrosis: possible mechanism of pulmonary vein reconnection
}

\author{
Aruna Arujuna*, Dennis Caulfield, Rashid Karim, Benjamin Knowles, Aldo Rinaldi, Michael Cooklin, Mark ONeill, \\ Kawal Rhode, Jaswinder Gill, Reza Razavi
}

From 2011 SCMR/Euro CMR Joint Scientific Sessions

Nice, France. 3-6 February 2011

\section{Background}

Wide area circumferential ablation (WACA) is used to achieve pulmonary vein isolation (PVI) for treatment of AF. AF recurrences associated with pulmonary vein reconnection are common.

\section{Purpose}

We assessed the hypothesis that acute PVI results from a combination of irreversible (necrosis) and reversible (interstitial oedema) tissue damage at the left atrial (LA)-pulmonary vein (PV) junction as evaluated by cardiac magnetic resonance $(\mathrm{CMR})$ imaging.

\section{Methods}

15 patients with paroxysmal atrial fibrillation (PAF) underwent CMR scanning pre and immediately post WACA. 12 patients (4 male; mean age $56 \pm 11$ years) had good quality images for delayed enhancement DE (necrosis) [Figure 1a,1b] and high T2-weighted signal (oedema) [Figure 1c,1d]. Images were analysed to quantify the circumferential extent of lesion formation with both imaging sequences. Clinical follow-up results at 6 months were then correlated with the MR findings.

\section{Results}

Twenty four pairs of pulmonary veins were electrically isolated during the ablation and subsequently divided into no recurrences and recurrences of AF; quantifying the percentage $(\%)$ circumferential lesion of DE, high T2-weighted signal and DE $+\mathrm{T} 2$. Patients free from AF at follow-up ( $n=7$; 14pairs of PV) had mean \pm SD of $\mathrm{DE}$ and high T2-weighted signal of $73.2 \pm 25.4 \%$ and $19.3 \pm 21.9 \%$ respectively. Patients with recurrences $(\mathrm{n}=5$; 10pairs of PV) had mean \pm SD of DE and high T2-weighted signal of $46.5 \pm 25.9 \%$ and $47.5 \pm 28.3 \%$. Between the two groups, the statistical difference in the $\mathrm{T} 2$-weighted means $(\mathrm{p}=0.01)$ was twice that of the DE means $(\mathrm{p}=0.02)$. No statistical difference was seen in the DE+T2 means. On visual assessment areas of high T2 signal (oedema) not only overlapped with areas of DE but also filled in gaps between areas of $\mathrm{DE}$, producing in combination almost circumferential lesions in all PVs.

\section{Conclusion}

CMR scans performed post ablation confirms DE (necrosis) and high T2 signal (oedema) forming a near complete ring around the pulmonary veins contributing to electrical isolation. In patients with recurrent atrial fibrillation, more of this ring was composed of high T2-weighted signal than DE. This may provide evidence for immediate post procedural oedema without necrosis being the mechanism of pulmonary vein reconnection and recurrence of AF post catheter ablation during follow-up. 

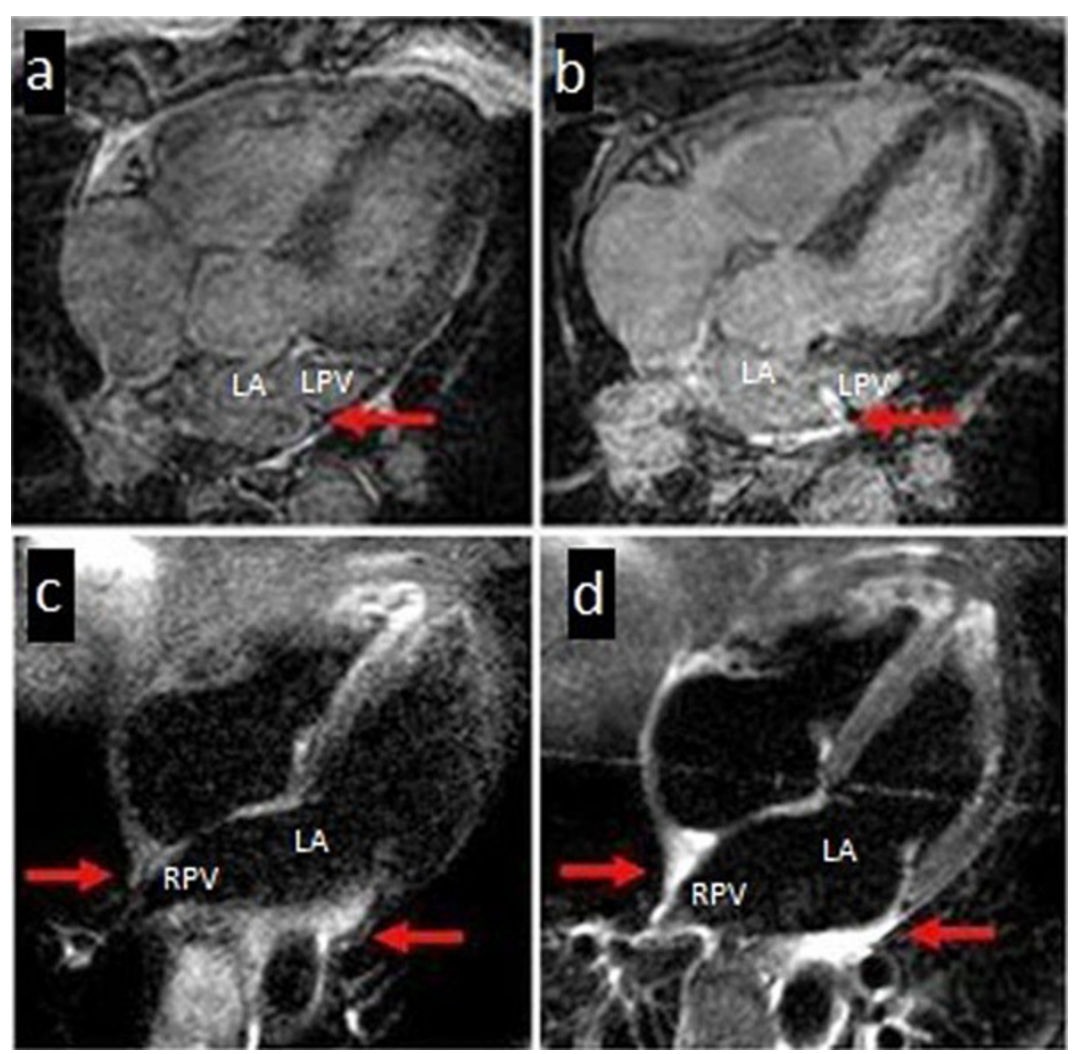

Figure 1 Demonstrating images pre- and post-ablation for late enhancement - figure 1a, 1b and T2-W oedema imaging pre- and post-procedure - figure $1 \mathrm{c}, 1 \mathrm{~d}$.

Published: 2 February 2011

doi:10.1186/1532-429X-13-S1-M8

Cite this article as: Arujuna et al: Acute pulmonary vein isolation

lesions consist of interstitial oedema and tissue necrosis: possible

mechanism of pulmonary vein reconnection. Journal of Cardiovascular

Magnetic Resonance 2011 13(Suppl 1):M8.

\section{Submit your next manuscript to BioMed Central} and take full advantage of:

- Convenient online submission

- Thorough peer review

- No space constraints or color figure charges

- Immediate publication on acceptance

- Inclusion in PubMed, CAS, Scopus and Google Scholar

- Research which is freely available for redistribution 